\title{
Cadernos de planejamento de professoras como documento histórico
}

\author{
Cadernos de planificación de profesoras como documento histórico \\ Teacher planning documents as a historical document
}

\section{Lucas Gonçalves Soares ${ }^{1}$}

\begin{abstract}
Resumo
Este trabalho é parte de uma pesquisa em andamento a nível de Doutorado pelo Programa de Pós-graduação em Educação da Universidade Federal de Pelotas, orientada pela Prof ${ }^{a}$. Dr ${ }^{\mathrm{a}}$. Eliane Peres. O estudo insere-se no campo da História da Educação, tendo como objetivo geral investigar em cadernos de planejamento de professoras dos anos iniciais, a partir da década de 1960, o trabalho com a leitura literária suas mudanças, ausências e permanências. Neste texto, pretendo apresentar as fontes de pesquisa/documentos históricoscadernos de planejamentos de professoras - todos destinados ao que hoje denominamos anos iniciais, totalizam 225, provenientes do acervo: Cadernos de planejamento (diários de classe) de professoras, pertencente ao grupo de pesquisa da História da Alfabetização, Leitura e Escrita e dos Livros Escolares - HISALES. Tais cadernos, contêm planejamentos manuscritos nos quais são registradas as atividades cotidianas previstas pela professora, feitos previamente às aulas, ou seja, são os planejamentos diários para rotina em sala de aula. A motivação para a escolha deste tema de pesquisa justifica-se, sobretudo, pelo fato de que nos planejamentos de professoras contém a intenção do que poderia ser desenvolvido na prática com os alunos aos quais se destinam. Por isso, acredito que através do levantamento de dados nesses documentos seja possível analisar de que maneira a leitura literária se inseria nos planejamentos ao longo das décadas de 1960 até 2010.
\end{abstract}

Palavras-chave: Cadernos de planejamento, documento histórico, História da Educação

\section{Resumen}

Este trabajo forma parte de una investigación en curso a nivel de Doctorado por el Programa de Postgrado en Educación de la Universidad Federal de Pelotas, orientada por la Prof ${ }^{a}$. Dr ${ }^{a}$. Eliane Peres. El estudio se inserta en el campo de la Historia de la Educación, teniendo como objetivo general investigar en cuadernos de planificación de profesoras de los años iniciales, a partir de la década de 1960, el trabajo con la lectura literaria sus cambios, ausencias y permanencias. En este texto, pretendo presentar las fuentes de investigación cuadernos de planificaciones de profesoras - todos destinados a lo que hoy denominamos años iniciales, totalizan 225, provenientes del acervo: Cuadernos de planificación (diarios de clase) de profesoras, perteneciente al grupo de investigación de la Historia de la Alfabetización, Lectura y Escritura y de los Libros Escolares - HISALES. Tales cuadernos, contienen planeamientos manuscritos en los que se registran las actividades cotidianas previstas por la profesora, hechas previamente a las clases, o sea, son los planes diarios para rutina en el aula. La motivación para la elección de este tema de investigación se justifica sobre todo por el hecho de que en los planes de profesoras contiene la intención de lo que podría ser desarrollado en la práctica con los alumnos a los que se destinan. Por eso, creo que a través del levantamiento de datos en esos documentos es posible analizar de qué manera la lectura literaria se inserta en los planes a lo largo de las décadas de 1960 hasta 2010.

Palabras clave: Cuadernos de planificación, documento histórico, Historia de la educación

\begin{abstract}
This work is part of an ongoing research at the Doctoral level by the Postgraduate Program in Education of the Federal University of Pelotas, guided by Prof ${ }^{a}$. Dr ${ }^{a}$. Eliane Peres. The study is part of the History of Education, with the general objective of investigating the changes, absences and permanencies in the planning books of teachers from the beginning of the 1960s. In this text, I intend to present the sources of research / historical documents - notebooks of teacher's plans - all destined to what we now call the initial years, totaling 225 from the collection: Planning notebooks (class diaries) of teachers, belonging to the group of research on the History
\end{abstract}

${ }^{1}$ Doutorando em Educação; Universidade Federal de Pelotas; Pelotas, Rio Grande do Sul, Brasil; luks_gs21@hotmail.com 
of Literacy, Reading and Writing, and School Books - HISALES. These notebooks contain handwritten plans in which the daily activities planned by the teacher are recorded, made prior to classes, that is, they are the daily routine planning in the classroom. The motivation for choosing this research theme is justified, in particular, by the fact that in teacher plans it contains the intention of what could be developed in practice with the students for whom they are intended. For this reason, I believe that by collecting data in these documents, it is possible to analyze how the literary reading was inserted in the plans during the decades of 1960 until 2010.

Keywords: Planning notebooks, historical document, History of Education

\section{Introdução}

Neste texto ${ }^{2}$ problematizo o uso de cadernos de planejamento de professoras como fonte/objeto de pesquisa, como documento histórico, em consonância com o movimento de ampliação das fontes de pesquisa na História da Educação. Dessa forma, o estudo insere-se no campo da Educação, para ser mais específico, no campo da História da Educação, tendo como objetivo investigar em cadernos de planejamento de professoras dos anos iniciais, a partir da década de 1960, o trabalho com a leitura literária suas mudanças, ausências e permanências.

A motivação para a escolha deste tema de pesquisa justifica-se, sobretudo, pelo fato de que nos cadernos de planejamentos de professoras ${ }^{3}$,ou diários de classe $^{4}$, contém a intenção do que seria desenvolvido na prática com os alunos aos quais se destinam. Por isso, acredito na potencialidade desses documentos e que através do levantamento e análise de dados seja possível entender de que maneira a leitura literária se inseria no planejamento dessas professoras ao longo das décadas, estabelecendo/destacando/registrando ausências, permanências e mudanças.

Os documentos - cadernos de planejamentos de professoras analisados pertencem ao acervo cadernos de planejamento (diários de classe) de professoras salvaguardado pelo grupo de pesquisa da História da Alfabetização, Leitura e Escrita e dos Livros Escolares (Hisales) ${ }^{5}$.

\footnotetext{
${ }^{2}$ Este artigo é parte de uma pesquisa em andamento curso de Doutorado do Programa de Pós-graduação em Educação da Universidade Federal de Pelotas (UFPel), 2017-2020.

${ }^{3} \mathrm{~A}$ palavra é utilizada no feminino, porque o acervo conta somente com cadernos de planejamento de professoras.

${ }^{4}$ Embora esse recurso seja nomeado por alguns pesquisadores e professores como "diário de classe", optei pelo uso do termo Caderno de planejamento.

${ }^{5}$ O HISALES - História da Alfabetização, Leitura, Escrita e dos Livros Escolares - é um centro de memória e de pesquisa, cadastrado no CNPq desde junho de 2006. Coordenado pelas professoras Dra. Eliane Peres e Dra. Vania Grim Thies, é vinculado ao Programa de Pós-Graduação em Educação (PPGE) da Faculdade de Educação (FaE) da Universidade Federal de Pelotas (UFPel) e reúne alunos de graduação e de pós-graduação. Disponível em: <http://wp.ufpel.edu.br/hisales/>. Acesso em: 15 mar. 2018.
} 
Tal grupo constituiu-se, ao longo dos seus 12 anos de existência, como um importante centro de documentação para a manutenção e memória da alfabetização, leitura e escrita podendo ser consultado fisicamente.

Com o intuito de situar o leitor, este artigo foi organizado da seguinte forma: na primeira parte discuto a ampliação das fontes de pesquisa na História da Educação, relacionando com a pesquisa em andamento. $\mathrm{Na}$ segunda parte caracterizo a pesquisa que ora proponho, apresentando os procedimentos metodológicos, detalhando a coleta e organização $\underline{\text { dos dados, }}$ problematizando as potencialidades do estudo, por último teço as considerações finais.

\section{História da educação e os cadernos de planejamento de professoras como fontes de pesquisa}

O campo da História da Educação está sempre inovando e por isso, tem seu domínio de pesquisa cada vez mais ampliado. Considerando que a amplitude e a pluralidade dos processos educativos, ocorrem de maneira formal e informal desde os primórdios da humanidade, convenciona-se o termo "Histórias da Educação" (LOPES E GALVÃO, 2010, p. 10), dado a pluralidade de possibilidades de pesquisas nesse campo. Entendo então, que os processos escolares, os materiais utilizados/produzidos nos processos de ensinoaprendizagem, as políticas, as relações, entre outros aspectos que envolvem a educação formal e informal, ao longo dos anos, forneceram/fornecem incontáveis objetos, documentos e outros recursos que podem, dependendo do interesse, curiosidade e motivação do investigador e das perguntas que esse elaborar se constituírem como fonte/objeto de pesquisa. Quando me refiro ao caderno de planejamento como objeto, tratam-se de estudos que exploram a materialidade, a forma, o conteúdo e a estrutura do caderno. E, como fonte, pesquisas que exploram especificamente um conteúdo, neste caso - o trabalho com a leitura literária.

Ainda segundo as autoras Lopes e Galvão (2010), o cotidiano escolar, a materialidade dos objetos, as relações que permeiam a rotina da escola "[...] de tão falada, vista, vivida, incorporada, acostumamo-nos com essa realidade. Com isso, corremos o risco de naturalizála." (p.11). As autoras complementam afirmando que: 


\begin{abstract}
Apesar dessa familiaridade, muito do que ocorre no universo da educação ainda é pouco conhecido pelos pesquisadores - e mesmo pelos professores. Imersos nesse mundo, nem sempre eles conseguem perceber o que os estudantes pensam, o que ensinar e aprender, qual é o sentido de cada uma das cenas que compõem o dia a dia da escola, que significados possuem a leitura e a escrita, o conhecimento e o saber. (LOPES E GALVÃO, 2010, p. 11).
\end{abstract}

Dessa forma, os processos educativos, o cotidiano da escola, os sujeitos, as experiências vivenciadas na educação formal e informal tendem a se naturalizar. A naturalização não significa compreensão, por isso, a importância das pesquisas no campo da História da Educação. O interesse do pesquisador/historiador e a atenção à potencialidade da fonte/objeto, é o que determina a produção da História, pois quando deixamos de nos questionar e de questionar, também deixamos de refletir sobre os métodos de ensino, os materiais didáticos, as relações professor-aluno, os conteúdos ensinados, os materiais produzidos em sala de aula e porque não dizer sobre a temática desse estudo, qual seja: Possíveis mudanças, ausências e permanências nas práticas de leitura literária nos planejamentos de professoras dos anos iniciais a partir da década de 1960 até a década de 2010, a fim de entender os processos de ensino de diferentes épocas e as variadas práticas escolares.

Os cadernos de planejamento de professoras dos anos inicias, os quais me refiro nesse texto, são aqui tratados como documento histórico e pertencem ao acervo cadernos de planejamento (diários de classe) de professoras, o mais antigo data de 1965 e o mais atual de 2016, o limite dado pelo acervo justifica o recorte temporal.

Esses documentos foram produzidos por sujeitos - professoras dos anos inicias - em diferentes épocas e em diferentes contextos, e por conterem, como já frisei anteriormente, o registro da intencionalidade de cada aula ao longo de um período, certamente são permeados de dados que poderão produzir uma história das práticas de leitura literária a partir dos cadernos investigados. Dessa forma, enquanto historiador, estou me colocando no compromisso social de trazer voz a estes documentos. O autor Michel De Certeau, em sua obra A escrita da história (1982), quando trata sobre o lugar social ressalta a atividade de pesquisa. Certeau afirma que a atividade de pesquisa histórica está inserida em um lugar, no qual de acordo com os seus interesses definirá o que pode vir a ser feito e o que não é permitido. O lugar social que se insere esse estudo é a sala de aula em diferentes épocas (1965 - 2016), esse lugar social, pode ser expresso na produção singular de cada caderno de planejamento. Através destes apontamentos Certeau nos deixa claro sobre o peso que a instituição e o lugar social dos indivíduos possuem sobre a construção do discurso do historiador. Ou seja, os cadernos de planejamentos das professoras dos anos iniciais, 
produzidos sobre a influência da instituição e do lugar social definirão, através da operacionalização escolhida, o meu discurso, aqui falo do lugar de historiador. Além disso, e antes disso - do discurso - há a necessidade dos usos de técnicas e métodos científicos, para legitimarem a História e o que será nela produzido - o que vai caracterizar a operação historiográfica.

Quando nos propomos a fazer História, ou seja, como uma prática, há a necessidade de uma técnica para a realização da produção historiográfica (CERTEAU,1982, p. 78). Certeau diz que o fazer do historiador se assemelha ao de um operário. Esse processo deve obedecer regras estabelecidas pela academia, inclusive, se for necessário o cruzamento com outros objetos/fontes já estudados e por último, caberá ao pesquisador/historiador realizar o transporte do seu produto do campo cultural para o histórico. A descrição da prática muito se assemelharia à ação de um metalúrgico, como o autor compara em seus escritos (CERTEAU,1982, p. 79). Daí o termo operação historiográfica, o que me proponho a realizar. Dessa forma, caberá a mim, enquanto historiador, a seleção das fontes, a escolha de técnicas metodológicas para operacionalizar as fontes, para que seja possível a coleta e análise dos dados e por fim, a escrita de um discurso sobre as mudanças, ausências e permanências da leitura literária no planejamento das professoras investigadas.

\subsection{Corpus de pesquisa - acervo de cadernos de planejamento de professoras alfabetizadoras}

O acervo ao qual pertencem os cadernos referidos aqui, como já dito anteriormente, é salvaguardado pelo grupo de pesquisa da História da Alfabetização, Leitura e Escrita e dos Livros Escolares (Hisales) ${ }^{6}$. O Hisales constituiu-se, ao longo dos seus 12 anos de existência, como um importante centro de documentação para a manutenção e memória da alfabetização, leitura e escrita podendo ser consultado fisicamente por diferentes pesquisadores. é um centro de memória e pesquisa e tem concentrado esforços na coleta de materiais ligados à alfabetização $^{7}$ (cadernos de alunos em fase de alfabetização, livros destinados ao ensino inicial da leitura e da escrita, cadernos de planejamento de professoras alfabetizadoras (diários de classe), materiais pedagógicos, objetos pertencentes às escolas e um acervo específico de

\footnotetext{
${ }^{6}$ O HISALES - História da Alfabetização, Leitura, Escrita e dos Livros Escolares - é um centro de memória e de pesquisa, cadastrado no CNPq desde junho de 2006. Coordenado pelas professoras Dra. Eliane Peres e Dra. Vania GrimThies, é vinculado ao Programa de Pós-Graduação em Educação (PPGE) da Faculdade de Educação (FaE) da Universidade Federal de Pelotas (UFPel) e reúne alunos de graduação e de pós-graduação. Disponível em: <http://wp.ufpel.edu.br/hisales/>. Acesso em: 15 mar. 2018.

${ }^{7}$ Embora a chamada de doações, no início tenha sido somente para cadernos de alfabetização, as doações de planejamento de outras séries foram chegando e o acervo foi ampliado.
} 
livros didáticos, produzidos por autoras gaúchas entre os anos de 1940-1980. Esses materiais chegam ao grupo de duas maneiras: por meio de doações e através de compras, principalmente, em sebos e lojas virtuais, por parte dos integrantes do grupo. Ao chegarem, esses materiais passam por um processo de higienização e, posteriormente, são catalogados e organizados de acordo com os seus respectivos acervos.

Tal grupo reúne alunos e pesquisadores da graduação e da pós-graduação de diferentes áreas do conhecimento. Um dos objetivos do grupo de pesquisa é "constituir acervos para manutenção da história e da memória da alfabetização" (PERES, 2011), principalmente do/no Rio Grande do Sul.

As pesquisas que vêm sendo realizadas no Hisales inserem-se basicamente em três eixos de estudos, são eles: I) investigações sobre a história alfabetização; II) pesquisas acerca das práticas escolares e não-escolares de leitura e escrita;III) análises da produção, circulação e utilização de livros escolares elaborados por autoras gaúchas, especialmente entre os anos de 1940-1980 (período de grande influência do Centro de Pesquisas e Orientações Educacionais (CPOE/SEC-RS)).

O referido grupo possui atualmente seis acervos: I) livros para o ensino inicial da leitura e da escrita; II) livros didáticos elaborados por autoras gaúchas entre os anos de 1940 e 1980; III) cadernos de alunos; IV) cadernos de planejamento de professoras alfabetizadoras(anos iniciais); V) materiais didático pedagógicos diversos/cultura material escolar; VI) materiais referentes às escritas ordinárias (agendas, cadernos de recordações, diários, cartas, etc.).

Os cadernos aos quais me refiro neste texto concentram-se no acervo cadernos de planejamento (diários de classe) de professoras, o qual contém cadernos de planejamentos manuscritos com registros das atividades cotidianas previstas pelas professoras, geralmente feitos previamente às aulas, ou seja, são os planejamentos diários das rotinas, exercícios e tarefas programadas para ser desenvolvidas com os alunos. No Rio Grande do Sul convencionou-se chamar esses cadernos de Diários de Classe.

No caso específico dos cadernos de planejamento, estes são catalogados por década, por exemplo: o primeiro caderno catalogado da década de 1960, quando o caderno chega ao HISALES, é preparado para catalogação - os cadernos considerados na pesquisa são classificados de 2 formas: 
a) Cadernos de Planejamento do Ciclo de Alfabetização (CPA), possuem planejamento de aulas para turmas em fase de Alfabetização $-1^{\mathrm{a}}$ série $/ 1^{\circ}$ ano $/ 2^{\circ}$ ano ou $3^{\circ}$ ano ${ }^{8}$.

b) Cadernos de Planejamento de Outras Séries (CPOS), como a identificação já sugere, neles são encontrados planejamento de aulas para turmas de outras séries (Educação Infantil, $2^{\mathrm{a}}$ série, $3^{\mathrm{a}}$ série, $4^{\mathrm{a}}$ série, $5^{\mathrm{a}}$ série, $8^{\mathrm{a}}$ série, Curso Normal, Educação de Jovens e Adultos, entre outros).

Quando catalogados, os cadernos recebem uma etiqueta que contém classificação (CPA, CPOS), número que corresponde a quantidade de cadernos desse tipo naquele ano, ano a que se refere e número da coleção - caso pertençam a um conjunto de mais cadernos de uma mesma professora.

Atualmente $^{9}$, o acervo de cadernos de planejamento (diários de classe) de professoras tem 254 cadernos (CPA e CPOS) e estão organizados conforme a década em que foram produzidos/usados pelas professoras. O quadro 01 apresenta o acervo de cadernos de planejamento do Hisales ${ }^{10}$.

Quadro 01 - Detalhamento do acervo cadernos de planejamento de professoras ${ }^{11}$

\begin{tabular}{|c|c|c|}
\hline \multicolumn{3}{|c|}{$\begin{array}{c}\text { CADERNOS DE PLANEJAMENTO (DIÁRIOS DE CLASSE) DE } \\
\text { PROFESSORAS } \\
\text { Data de atualização: novembro de } 2018\end{array}$} \\
\hline \multirow[t]{2}{*}{ Década } & \multicolumn{2}{|c|}{ Quantidade } \\
\hline & Ciclo de alfabetização & Outras séries \\
\hline 1960 & 02 & 02 \\
\hline 1970 & 04 & 09 \\
\hline 1980 & 21 & 23 \\
\hline 1990 & 36 & 30 \\
\hline 2000 & 62 & 34 \\
\hline 2010 & 31 & - \\
\hline TOTAL & 156 & 98 \\
\hline TOTAL GERAL & \multicolumn{2}{|c|}{254} \\
\hline
\end{tabular}

Fonte: Quadro elaborado pelo autor a partir das tabelas do HISALES

Focado em conhecer mais sobre esse objeto/fonte de estudo, realizei uma busca, no intuito de localizar trabalhos acadêmicos que utilizam o caderno de planejamento de professores como fonte/objeto de pesquisa, investigamos sites indexadores reconhecidos ${ }^{12}$ na área de pesquisa acadêmica e científica. Para a pesquisa, busquei títulos a partir dos

\footnotetext{
${ }^{8}$ Embora o $3^{\circ}$ ano faça parte do Ciclo de Alfabetização, ainda não há nenhum exemplar dessa etapa no acervo. ${ }^{9}$ Tomando como base janeiro de 2018.

${ }^{10}$ Disponível em: <http://wp.ufpel.edu.br/hisales/?page id=14>. Acesso em: 12 de fevereiro de 2018.

${ }^{11}$ Elaborada levando em consideração as doações catalogadas até o presente momento.

${ }^{12}$ Banco de Teses e Dissertações da CAPES, Biblioteca Digital de Teses e Dissertações da PUC/RS, Biblioteca Digital de Periódicos da UFPR, Dialnet, Elsevier, Lume - Repositório Digital da UFRGS, Portal Domínio Público, Sistema Pergamum de Bibliotecas da UFPel, Periódicos da CAPES. Na área da Educação, já foram pesquisadas as seguintes Revistas: Educar em Revista, Revista Brasileira de História da Educação - RBHE, Revista História da Educação, Revista Teias.
} 
descritores "Caderno de planejamento de professores" e "Caderno de professores". A partir disso, localizei trabalhos com temáticas semelhantes, mas poucos utilizando como objeto/fonte o caderno de planejamento de professoras. Essa escassez de produções acadêmicas corrobora com o que afirma PERES (2017): “Construir referenciais de exploração e análise dessa fonte/objeto de investigação é um grande desafio para a comunidade acadêmica interessada nesses estudos." (p. 29-30).

O Hisales, com seus pesquisadores, busca produzir tais referencias, tanto é que, as duas produções acadêmicas com esse tipo de fonte/objeto que aparecerem repetidas vezes como resultado de busca, foram desenvolvidas por integrantes do próprio grupo, detalharei a seguir.

Essas importantes pesquisas foram orientadas pela professora doutora Eliane Peres, em nível de mestrado, constituídas no âmbito do grupo Hisales e defendidas no Programa de pós-graduação em Educação (PPGE) da Faculdade de Educação (FaE) da Universidade Federal de Pelotas (UFPel). As duas dissertações utilizam como fontes principais de pesquisa cadernos de planejamento de professoras pertencentes ao acervo do HISALES, ou seja, o mesmo acervo ao qual pertencem os cadernos desse projeto que apresento.

A primeira delas, por ordem cronológica, defendida em 2013, é de autoria da pesquisadora Gisele Ramos Lima e intitulada: Uma análise dos exercícios com sílabas em Diários de Classe de professoras alfabetizadoras (1973-2010). A pesquisa, inserida no campo da História da alfabetização, apresenta uma análise sobre os tipos e a recorrência de atividades envolvendo sílabas, para tanto, a pesquisadora utilizou 68 cadernos de planejamento de professoras alfabetizadoras, que ela nomeou "Diários de Classe", como já mencionado anteriormente, esse termo é sinônimo e recorrentemente utilizado no estado do Rio Grande do Sul. Como recorte temporal esteve o período compreendido entre os anos de 1973 a 2010. Segundo a autora, o estudo é de cunho qualitativo, tendo como modelo epistemológico o paradigma indiciário proposto por Ginzburg (2011), que apresenta como pressuposto a busca de "vestígios", "pistas", "indícios" nos documentos pesquisados, objetivando encontrar nos detalhes o que é possível considerar como "elementos relevantes" para responder às questões da pesquisa. Lima (2013) faz uma relação dos tipos de exercícios específicos do trabalho com sílabas encontradas nos "diários de classe" ao longo do período estipulado por ela, com os métodos de ensino e revela que os "métodos tradicionais" de alfabetização nos planejamentos registrados nos Diários são mais presentes. Mostra também que as atividades mais recorrentes trabalhadas pelas professoras alfabetizadoras foram aquelas que privilegiam a cópia e a memorização de tais estruturas. 
A segunda pesquisa, de autoria de Cícera Vieira, datada em 2014, também defendida no PPGE/FaE/UFPel, tendo como título $O$ uso de cartilhas no processo de alfabetização: um estudo a partir de cadernos de planejamento de uma professora (1983 -2000) utilizou como fonte/objeto Cadernos de planejamento de uma única professora. A mesma atuava em uma turma multisseriada na zona rural, de um município da região sul do Rio Grande do Sul, desse conjunto, atualmente o maior do acervo, com 53 cadernos, foram utilizados para essa pesquisa os destinados à alfabetização - 23 deles correspondentes ao período de 1983-2000, o recorte é justificado pela autora pelo acesso às fontes que permitem uma análise longitudinal, o que possibilitou averiguar quais livros para o ensino inicial da leitura e da escrita foi utilizados ao longo de dezessete anos. Dessa forma, o estudo objetivou identificar e mapear quais livros destinados ao ensino inicial da leitura e da escrita foram utilizados como apoio na preparação das aulas. Após uma exaustiva coleta de dados, a pesquisadora fez um cruzamento com os livros didáticos disponíveis na região no período estabelecido, conseguindo um mapeamento bem satisfatório, concluindo que os cadernos de planejamento analisados traduzem uma representação da rotina da sala de aula e do cotidiano escolar, que é "possível observar uma sequência metodológica, que procurava seguir uma gradação das dificuldades de aprendizagem, iniciando pelo período preparatório, seguindo com as vogais, encontros vocálicos e sílabas." (VIEIRA, 2014, p.10).Quanto aos livros destinados ao ensino inicial da leitura e da escrita utilizados como apoio na preparação das aulas, a autora mapeou um conjunto de quatorze livros, sendo que os mais recorrentes foram: cartilhas Pirulito, Alegria de Saber e É Hora de Aprender. A partir daí Vieira, relacionada a metodologia expressa nesses livros com a prática da professora, concluindo que, “[...] apesar do debate em torno da alfabetização provocada pelos estudos da Psicogênese da Língua Escrita, de Ferreiro \& Teberosky (1999), e pelo conceito de letramento Soares (1998), a prática da professora continua embasada numa concepção associacionista de aprendizagem.” (VIEIRA, 2014, p. $10)$.

Nos dois trabalhos, mesmo com abordagens diferentes, observa-se um exaustivo manuseio, cópia e revisita aos documentos, ou seja, os cadernos de planejamentos são fontes/objetos de pesquisa que necessitam de uma dedicação que demanda bastante tempo do pesquisador. A seguir descrevo os procedimentos metodológicos que estão sendo utilizados na coleta dos dados para o estudo que estou me propondo a desenvolver.

\section{Procedimentos metodológicos: o trabalho de coleta de dados com cadernos de planejamentos}


Os cadernos de planejamento de professoras dos Anos Inicias são fontes singulares e podem nos dizer muito sobre o cotidiano do trabalho efetivado em sala de aula, fornecendo indícios/pistas das significativas mudanças ocorridas no decorrer da História da Educação. Desta forma, eles se constituem importantes documentos de pesquisa, segundo Viñao:

No bojo da ampliação da noção de documento, recentemente esse suporte da escrita escolar passou a ser valorizado. Os historiadores da educação, assim como os especialistas em currículo e formação de professores e os psicólogos, entre outros, preocupados em examinar o vivido na sala de aula, têm voltado para os cadernos, que passam a ser considerados importantes objetos ou fontes de pesquisa (2008, p. 7).

Considerando a relevância dessa fonte de pesquisa, os cadernos de planejamento são tratados aqui como documentos. Portanto trata-se de uma análise documental. A análise documental constitui-se como uma técnica decisiva e indispensável para pesquisas acadêmicas na área das ciências humanas, pois a maior parte das fontes escritas - ou não são quase sempre a base de um trabalho de investigação - o que não é diferente aqui. De acordo com Santos:

A pesquisa documental é realizada em fontes como tabelas estatísticas, cartas, pareceres, fotografias, atas, relatórios, obras originais de qualquer natureza pintura, escultura, desenho, etc.), notas, diários, projetos de lei, ofícios, discursos, mapas, testamentos, inventários, informativos, depoimentos orais e escritos, certidões, correspondência pessoal ou comercial, documentos informativos arquivados em repartições públicas, associações, igrejas, hospitais, sindicatos (2001, p.25).

Lüdke e André complementam dizendo:

A análise documental constitui uma técnica importante na pesquisa qualitativa, seja complementando informações obtidas por outras técnicas, seja desvelando aspectos novos de um tema ou problema (1986, p.38).

$\mathrm{Na}$ análise documental as realidades investigadas não são dadas prontas para serem descritas e interpretadas. São incertas e instáveis mostrando que "ideias e teorias não refletem, mas traduzem a realidade" (MORAES, 2004, p. 199).

Concordo com Moraes (2004, p. 242) quando afirma que "sabemos por experiência própria, que em toda tradução existe alguma traição e que em toda interpretação existe reconstrução por parte daquele que interpreta”. Isso se aplica muito apropriadamente à análise documental, pois "é impossível fazer uma pesquisa na qual se almeje a neutralidade do pesquisador e a objetividade da análise. Toda análise é subjetiva, fruto da relação íntima do pesquisador com seu objeto pesquisado". 
Como integrante do grupo Hisales, já conhecia o acervo de planejamento de professoras, contudo, meu primeiro contato como pesquisador ocorreu apenas em dezembro de 2016, após aprovação para o Doutorado, quando comecei a coleta de dados. Deparei-me com cadernos da década de 1960 - o primeiro datado de 1965 -, até a década de 2010, sendo o mais atual datado de 2016.

As etapas da coleta de dados que realizei são representadas no esquema abaixo:
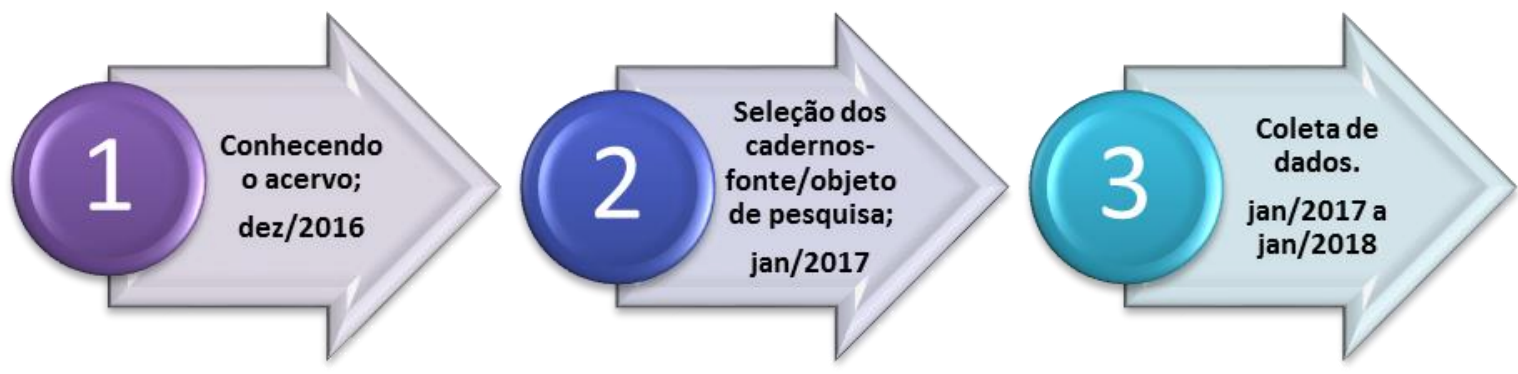

Figura 01 - Esquema com as etapas da coleta de dados Fonte: Figura elaborada pelo autor.

Após entender a organização do material, pensando em meu objetivo, qual seja: Investigar o trabalho com a leitura literária, suas possíveis mudanças, ausências e permanências em cadernos de planejamento de professoras dos anos iniciais, a partir da década de 1960 até 2010 - optei por um recorte para o estudo - utilizar apenas os cadernos de planejamento de professoras de Anos Iniciais do Ensino Fundamental, ou seja, $1^{\mathrm{a}}$ a $4^{\mathrm{a}}$ série ou $1^{\circ}$ ao $5^{\circ}$ ano, logo, os cadernos de outra natureza (caderno de testes, caderno de cantos, entre outros) e caderno de planejamento da Educação Infantil e da Educação de Jovens e Adultos, serão desconsiderados. Ainda nessa primeira etapa senti a necessidade de elaborar um quadro único com os cadernos, visto que, meu intuito não era a separação entre deles - Alfabetização e de Outras Séries (CPA; CPOS) - e sim, cadernos de planejamento dos anos iniciais.

O termo multisseriada foi utilizado para designar aqueles cadernos com planejamento que se destinam a mais de uma série/ano, o que era muito comum em escolas no campo (rurais). Os cadernos que não tem identificação de série/ano mas, mesmo assim,foram considerados na pesquisa, são aqueles que contém conteúdo adequado ao currículo préestabelecidos para os anos iniciais.

Foram desconsiderados 29 cadernos/documentos, visto que, o acervo conta com cadernos de todas as séries, inclusive do Ensino Fundamental II $-5^{\mathrm{a}}$ a $8^{\mathrm{a}}$ série $/ 6^{\circ}$ ao $9^{\mathrm{o}}$ ano; Curso de Magistério; Educação Infantil e Educação de Jovens e Adultos, além de cadernos de professora que tinham outra utilidade, tais como: Caderno de Avaliações, dicionários, entre outros. Optamos por desconsiderar estes, justificando-me na intenção primeira, qual seja: 
Cadernos de Planejamento, diários de classe para os Anos Iniciais. Assim, foram desconsiderados cadernos da Educação Infantil (8), de Alfabetização de Jovens e Adultos EJA (7), cadernos de testes e avaliação (2), Cadernos de planejamento de reforço (2), cadernos de Cantos (1), Cadernos de outras séries que não dos Anos Iniciais (8), relatórios e dicionários (1). Observa-se então que 29 cadernos não foram utilizados na coleta de dados, dessa forma o corpus de pesquisa vale-se de 225 cadernos. O quadro a seguir apresenta o corpus de pesquisa.

Quadro 02 - Cadernos de planejamento de professoras dos anos iniciais utilizados na coleta de dados

\begin{tabular}{|l|c|c|c|c|c|c|c|}
\hline $\begin{array}{l}\text { CADERNOS DE } \\
\text { PALNEJAMETOS DE }\end{array}$ & $\mathbf{1 9 6 0}$ & $\mathbf{1 9 7 0}$ & $\mathbf{1 9 8 0}$ & $\mathbf{1 9 9 0}$ & $\mathbf{2 0 0 0}$ & $\mathbf{2 0 1 0}$ & Total \\
\hline $\begin{array}{l}\text { PROFESSORAS } \\
\mathbf{1}^{\mathbf{0}} \text { ano }\end{array}$ & - & - & - & 1 & 5 & 16 & $\mathbf{2 2}$ \\
\hline $\mathbf{1}^{\mathbf{a}}$ série & 1 & 3 & 19 & 32 & 42 & 4 & $\mathbf{1 0 1}$ \\
\hline $\mathbf{2}^{\mathbf{o}}$ ano & - & - & - & - & 5 & 7 & $\mathbf{1 2}$ \\
\hline $\mathbf{2}^{\mathbf{a}}$ série & 2 & 3 & 6 & 8 & 13 & - & $\mathbf{3 2}$ \\
\hline $\mathbf{3}^{\mathbf{a}}$ série & - & 3 & 8 & 6 & 5 & - & $\mathbf{2 2}$ \\
\hline $\mathbf{4}^{\mathbf{a}}$ série & - & 1 & 4 & 9 & 5 & - & $\mathbf{1 9}$ \\
\hline Multisseriada & - & - & - & 3 & 10 & - & $\mathbf{1 3}$ \\
\hline Sem identificação & - & - & 1 & 2 & 1 & - & $\mathbf{4}$ \\
\hline Total década & $\mathbf{3}$ & $\mathbf{1 0}$ & $\mathbf{3 8}$ & $\mathbf{6 1}$ & $\mathbf{8 6}$ & $\mathbf{2 7}$ & $\mathbf{2 2 5}$ \\
\hline
\end{tabular}

Fonte: Quadro elaborado pelo autor

Como é possível observar no quadro 02, os cadernos são pertencentes a décadas diferentes, há um maior número de cadernos da década de 2000, década que tem a maior representatividade nesse estudo, com 86 cadernos, seguido da década de 1990 com 61 cadernos. A década de 1960 corresponde ao período com menos exemplares, apenas 3 diários. Embora o número de cadernos por década não seja uniforme ou proporcional, minha opção foi aceitar o limite da fonte, trabalhando com os indícios deixados pelos cadernos pertencentes a cada período.

Considerando apenas a etapa dos Anos iniciais ao qual se destina, há uma quantidade consideravelmente maior de cadernos destinados a $1^{\mathrm{a}}$ série (101 cadernos), evidencia-se também que, com exceção da $1^{\mathrm{a}}$ série, justamente pelo empenho do grupo em coletar cadernos de Alfabetização, nas outras séries/anos há um equilíbrio em quantidade de cadernos, $1^{\circ}$ ano (22 cadernos); $2^{\mathrm{o}}$ ano (12 cadernos); $2^{\mathrm{a}}$ série ( 32 cadernos); $3^{\mathrm{a}}$ série (22 cadernos); $4^{\mathrm{a}}$ série (19 cadernos); Multisseriada (13 cadernos) - Não identificados (4 cadernos).

Quanto à abrangência dos cadernos, o estudo refere-se somente a cadernos do Rio Grande do Sul. No entanto, abrangem municípios das regiões Sul (sua grande maioria - 172 cadernos); Campanha (5 cadernos); Metropolitana (1 caderno); Vale do Rio dos Sinos (10 
cadernos); Paranhana - Encosta da Serra (2 cadernos) Fronteira Noroeste (1 caderno) e Missões (1 caderno).

Talvez, pelo fato de o grupo HISALES ser sediado pela UFPel, os municípios vizinhos são os maiores doadores de cadernos. Piratini tem a maior representatividade, com 76 cadernos, sendo 53 desses pertencentes a uma mesma professora, tal conjunto, como já exposto, foi objeto de estudo de uma dissertação ${ }^{13}$. O município de Pelotas tem o segundo maior número de Cadernos de planejamento, com 55 cadernos. A distribuição geográfica dos cadernos não será relevante nesse estudo, contudo ajudam a compor o contexto da pesquisa.

As instituições as quais pertenciam os planejamentos são em sua maioria de redes municipais e estadual de ensino. Os nomes das escolas foram identificados de forma direta, quando o nome da mesma foi encontrado no caderno, e de forma indireta, quando o doador do material deu a informação. Em alguns casos ainda, não foi possível identificar o nome dessas escolas das maneiras mencionadas, sendo assim, o mesmo foi apurado por mim por meio de visita às secretarias de Educação ou via contato telefônico. Ao todo, foi possível constatar que os cadernos são de 58 instituições diferentes.

Não foi possível identificar a procedência institucional de 13 cadernos, dessa forma o número de escolas pode ser maior. Contudo, acredito que ausência dessa informação não comprometa a caracterização dos documentos.

Considerando a distribuição do número de cadernos de planejamento entre essas instituições e fazendo a relação entre rede pública e privada, constata-se que a grande maioria (200), pertencem à rede pública.

Ainda com relação às instituições que acho relevante destacar a qual espaço elas estão inseridas - urbano ou rural, ou seja, se a instituição é da cidade ou do campo. Averiguei que 122 pertencem à escolas localizadas na cidade e 90 a instituições situadas no campo e como já dito, em 13 cadernos não foi possível identificar a escola.

Percebe-se que não há uma diferença muito grande entre o número de cadernos pertencentes a cada zona (urbana ou rural), entendo que isso favoreça a pesquisa, pois traz equilíbrio, dado que há um senso comum de que as escolas localizadas no campo são mais carentes de recursos culturais, tais como livros de literatura.

\footnotetext{
${ }^{13}$ VIEIRA, Cícera Marcelina. O uso de cartilhas no processo de alfabetização: um estudo a partir de cadernos de planejamento de uma professora (1983-2000). 2014. 212f. Dissertação (Mestrado em Educação) - Faculdade de Educação, Universidade Federal de Pelotas, Pelotas, 2014. Disponível em: http://repositorio.ufpel.edu.br:8080/handle/prefix/2944. Acesso em: 12 de maio de 2017.
} 
Quanto às professoras, autoras dos cadernos de planejamento, as identificadas, totalizam 53, o que corresponde a 216 cadernos, ou seja, não foi possível identificar as autoras de 9 cadernos. Ainda com relação às autoras é possível destacar que uma delas elaborou o maior conjunto de cadernos pertencentes à pesquisa; Outra que chama atenção, atuou e possui cadernos correspondentes a cada fase da sua formação acadêmica começando no estágio do Magistério em 1999, passando pelo estágio da graduação em Pedagogia até a titulação de Mestre em Educação em 2008.

Após conhecimento e organização dos documentos, passei então, a pensar uma forma de registrar o que encontrava nos cadernos de planejamento optamos pelo uso do programa Word da Microsoft, utilizando uma tabela simples contendo os seguintes itens:

a) Professora: Neste item registrava o nome da professora, esse contido na tabela de registro dos diários de planejamento do acervo.

b) Identificação: Contém a identificação do caderno no acervo - CPA - Caderno de planejamento de Alfabetização, seu número de entrada e o ano ao qual se refere o diário, ou CPOS - Caderno de Planejamento de outras séries - seu número de entrada e o ano ao qual se refere o diário.

c) Materialidade do caderno: Aqui foram registrados os aspectos físicos do caderno referentes a capa, forma como o plano de aula era redigido, condições de preservação do suporte, número de folhas, estre outros. Cabe ressaltar que nesse item constatei que nem todos os planejamentos utilizam como suporte o caderno, as professoras utilizaram também pastas fichários, pasta de saquinhos plásticos, entre outros.

d) Observações: Esse é o item mais importante para a pesquisa, nele registrei todas as atividades que considerei relevantes para o estudo, transcrevi textos, descrição de práticas, nomes de livros, autores, entre outros aspectos que achei pertinentes.

A coleta de dados foi realizada de janeiro de 2017 a janeiro de 2018, totalizando em 196 páginas de material, essas foram impressas e encadernadas, logo em seguida analisadas, quadro a quadro.

Com o material produzido a partir da coleta nos cadernos realizei uma leitura cuidadosa e detalhada de todos os quadros refletindo sobre aspectos que poderiam ser relevantes para a pesquisa. Essa fase resultou em 6 tabelas, construídas no programa Excel da Microsoft, versão 2016. Cada tabela corresponde a uma década (1960; 1970; 1980; 1990; 2000 e 2010), os aspectos considerados formam:

a) Número $\left(\mathbf{N}^{\circ}\right)$ : Quando os cadernos foram selecionados numerei-os de 01 a 225, esse critério foi adotado para facilitar a identificação; 
b) Década: Nesse espaço é registrada a década a qual pertence o caderno;

c) Ano: Nessa coluna aparece o registro do ano ao qual pertence o caderno;

d) Identificação: Nesse item estão registradas as cotas que servem de identificação para os cadernos no grupo HISALES;

e) Série/Ano: Etapa a qual pertence o caderno analisado;

f) Títulos: Títulos das obras que foram lidas/registradas nos cadernos de planejamento pelas professoras;

g) Suportes: Suportes de leitura, ou seja, a leitura realizada pertencia a qual suporte (livro de literatura infantil, livro didático, folha fotocopiada, folha do próprio caderno, entre outros)

h) Enunciações: Essa coluna refere-se aos enunciados utilizados pelas professoras para nomear o momento destinado à leitura literária;

i) Gêneros: Essa coluna é destinada aos gêneros literários aos quais pertencem as leituras registradas nos diários de planejamento analisados;

j) Modos de ler: Nesse espaço consta os modos como as leituras foram realizadas (alunos leitores, leitura silenciosa, leitura oral, professora ledora, entre outros);

k) Espaços de leitura: Registro dos espaços/lugares onde as leituras foram realizadas;

l) Atividades desenvolvidas: Nessa coluna realizei o registro das atividades e conteúdos desenvolvidos a partir das leituras realizadas;

m) Estratégias: Registro das estratégias para oportunizar a leitura literária por parte das professoras (projetos, cantinho da leitura, momento fixo para leitura, entre outros);

n) Recursos para leitura: Para além dos suportes de leitura que outros recursos foram utilizados pelas professoras no momento de leitura (fantoches, sacolas de leitura, flanelógrafo, entre outros);

o) Autores: Esse espaço destina-se ao registro dos autores dos textos literários registrados nos planejamentos das professoras. (Só foi considerado nesse item os registros diretos realizados pelas professoras, ou seja, os nomes dos autores deveriam estar escritos no planejamento);

p) Município: Registro do município ao qual pertencia o caderno de planejamento.

O que a análise dos dados vai revelar? Considerando o grande volume de dados, acredito que os mesmos trazem uma pluralidade de possibilidades de pesquisa. Isso é uma história uma de práticas de leitura literária que contarei nos próximos anos.

\section{Considerações Finais}


Como já dito, o estudo está na fase inicial, por isso, não é possível fazer considerações mais consistentes com relação à análise dos dados. Entretanto é possível afirmar a relevância e potencialidade dos cadernos de planejamento de professoras - documentos - para as pesquisas que abordam temáticas relacionadas à Educação, principalmente aos pesquisadores/historiadores que preocupam-se com o trabalho de sala de aula. Os cadernos como documentos históricos podem ajudar a "contar" Histórias da Educação em diferentes épocas e contextos.

\section{Referências}

CERTEAU, Michel de. A Operação Historiográfica. In: CERTEAU, Michel de. A Escrita da História. Rio de Janeiro: Forense-Universitária, 1982.

GALVÃO, A. M. de O; BATISTA, A. A. G. Práticas de leitura, impressos, letramentos: uma introdução. In: GALVÃO, A. M. de O; BATISTA, A. A. G. (Org.). Leitura: práticas, impressos, letramentos. Belo Horizonte: Autêntica, 2010.

GIL, Antonio C. Métodos e Técnicas de Pesquisa Social.5. ed.São Paulo: Atlas, 1999.

LÜDKE, M.; ANDRÉ, M.E.D.A. Pesquisa em educação: abordagens qualitativas.São Paulo: EPU, 1986.

SANTOS, A. R. Metodologia Científica: a construção do conhecimento. 3. ed. Rio de Janeiro: DP\&A, 2000.

MORAES, M. C. Pensamento eco-sistêmico: educação, aprendizagem e cidadania no século XXI.Petrópolis: Vozes, 2004.

VIÑAO, A. Os cadernos escolares como fonte histórica: aspectos metodológicos e historiográficos. In: MIGNOT, Ana ChrystinaVenancio (Org.).Cadernos à vista: escola, memória e cultura escrita. Rio de Janeiro: UERJ, 2008. 